\title{
Identification of dermatophytes by sequence analysis of the rRNA gene internal transcribed spacer regions
}

\begin{abstract}
Correspondence
Tsung Chain Chang

tsungcha@mail.ncku.edu.tw
\end{abstract}

Received 3 September 2007

Accepted 25 January 2008

\author{
Hsin Chieh Li, ${ }^{1}$ Jean-Philippe Bouchara, ${ }^{2,3}$ Mark Ming-Long Hsu, ${ }^{4}$ \\ Richard Barton, ${ }^{5}$ Shuli Su ${ }^{1}$ and Tsung Chain Chang ${ }^{1}$
}

\author{
${ }^{1}$ Department of Medical Laboratory Science and Biotechnology, College of Medicine, National \\ Cheng Kung University, Tainan, Taiwan, ROC \\ ${ }^{2}$ Host-Pathogen-Interaction Study Group, UPRES-EA 3142, Angers University, Angers, France \\ ${ }^{3}$ Laboratory of Parasitology and Mycology, University Hospital, Angers, France \\ ${ }^{4}$ Department of Dermatology, College of Medicine, National Cheng Kung University, Tainan, \\ Taiwan, ROC \\ ${ }^{5}$ Institute of Molecular and Cellular Biology, School of Biochemistry and Microbiology, \\ University of Leeds, Leeds, UK
}

\section{INTRODUCTION}

Dermatophytes are keratinophilic fungi capable of causing dermatophytosis and are among the most adaptable parasitic associates of humans. Dermatophytes are classified in three anamorphic genera: Epidermophyton, Microsporum and Trichophyton (Weitzman \& Summerbell, 1995). Classical parameters for the identification of dermatophytes

Abbreviation: ITS, internal transcribed spacer.

The GenBank/EMBL/DDBJ accession numbers for the ITS sequences of dermatophytes reported in this study are D0860729, D0860737, DQ860739, Da860747, D0860749, D0860753, DQ860755, D0860762, DQ860768, DQ860769, D0860773, D0860774, DQ860776, DQ860778, DQ860784, D0860785, DQ860794, Da860802, Da860804, Da860812, DQ860814, DQ860818, DQ860820, DQ860827, D0860833, DQ860834, EF078476, EF078481 and EU362731-EU362734. include clinical features, culture characteristics, microscopic morphology and physiological test results. However, identification of dermatophytes sometimes remains difficult or uncertain due to their overlapping phenotypic characteristics, variability and pleomorphism (Gräser et al., 1999b, 2000b; Weitzman \& Summerbell, 1995).

Molecular approaches have been developed to provide more rapid and accurate alternatives for dermatophyte identification. These methods include gene-specific PCR (Kamiya et al., 2004; Kanbe et al., 2003a; Liu et al., 2001; Yoshida et al., 2006), RFLP analysis (Kamiya et al., 2004; Kanbe et al., 2003b; Leon-Mateos et al., 2006; Mochizuki et al., 2003), sequencing of the large submit rRNA gene (Ninet et al., 2003) or the chitin synthase-encoding gene (Kano et al., 2000), PCR fingerprinting (Gräser et al., 2000a, b) and DNA hybridization (El Fari et al., 1999). 
Sequencing of the internal transcribed spacer (ITS) regions (Gräser et al., 1999a, b, 2000a, b; Kaszubiak et al., 2004; Makimura et al., 1998, 1999, 2001; Mochizuki et al., 1999; Sharma et al., 2006) has proved to be a useful method for phylogenetic analysis and identification of dermatophytes. However, several strongly ecologically and phenotypically separated Trichophyton species may have only a small number of nucleotide differences in the ITS regions (Summerbell et al., 1999). The aim of this study was to evaluate the feasibility of sequencing the ITS1 and ITS2 regions for identification of 17 dermatophyte species, using a collection of reference strains and clinical isolates.

\section{METHODS}

Fungal strains. A total of 62 reference strains (17 species) and 126 clinical isolates of dermatophytes were analysed in this study (Table 1). Reference strains were obtained from the American Type Culture Collection (ATCC), USA, the Bioresources Collection and Research Center (BCRC), Taiwan, the Belgian Co-ordinated Collections of Micro-organisms (BCCM/IHEM), Belgium, and the Centraalbureau voor Schimmelcultures (CBS), The Netherlands. Clinical isolates were obtained from the Laboratory of Parasitology and Mycology, University Hospital, Angers, the Mycology Reference Centre, University of Leeds, and the National Cheng Kung University Hospital, Tainan. Clinical isolates, which were recovered from a variety of specimens including skin, nail and hair, were identified by microscopic and macroscopic characteristics (De Hoog et al., 2000; Larone, 2002). The species names used in this study were in agreement with current taxonomy proposed by Gräser et al. (2006), except Trichophyton terrestre and Trichophyton soudanense that were not considered as distinct species by them. The origin of the clinical isolates of the Trichophyton mentagrophytes complex is included in Table 1. Fungal strains were grown on Sabouraud dextrose agar (Difco) and incubated at $30{ }^{\circ} \mathrm{C}$ until there was evidence of hyphal growth.

Amplification and sequencing of the ITS regions. Fungal DNA extraction, ITS amplification using fungal universal primers ITS1 and ITS4, and sequencing of the PCR products were as described previously (Hsiao et al., 2005). The sequences of the 18S, 5.8S and $28 \mathrm{~S}$ rRNA gene regions were excluded to give the exact ITS1 and ITS2 sequences (Hsiao et al., 2005).

Construction of an ITS sequence database. An in-house database comprising ITS sequences of type, neotype or syntype strains was constructed from the following strains (GenBank accession numbers for ITS1 and ITS2 sequences are given in parentheses): Microsporum nanum CBS 314.54 (DQ860729 and DQ860794), Microsporum persicolor CBS 871.70 (DQ860737 and DQ860802), Trichophyton erinacei CBS 511.73 (EF078476 and EF078481), Trichophyton interdigitale BCRC 31782=CBS 642.73=ATCC $28146($ DQ860739 and DQ860804), T. mentagrophytes CBS 318.56 (Z97995), Trichophyton tonsurans ATCC 56186 (DQ860762 and DQ860827), and T. soudanense ATCC 64654 (DQ860755 and DQ860820) and Trichophyton violaceum CBS 374.92 (AJ270810). The ITS sequences with a prefix of 'DQ' and 'EF' were sequenced in this study and submitted to GenBank (National Center for Biotechnology Information, USA), while other reference sequences were obtained from GenBank. The database was constructed using Vector NTI Advance 9 software (Invitrogen).

Identification of dermatophytes by ITS sequencing. Species identification was made by sequence comparison with reference sequences in the constructed ITS database. Multiple ITS sequence alignment, and calculation of the similarity score between the query sequence and reference sequence, were performed by using the algorithms of 'Align' and 'Similarity', respectively, of the Vector NTI Advance 9 software. Species identification was determined from the best-scoring reference sequence of the similarity output that had an identity of $\geqslant 97 \%$ with the query sequence. For species that do not have type or neotype strains, species identification was made by searching databases using the BLASTN algorithm of the BLAST sequence analysis tool (http://www.ncbi.nlm.nih.gov/BLAST/) from the National Center for Biotechnology Information. Strains producing discrepant results between morphological identification and ITS sequence analysis were further analysed by sequencing the D1-D2 region of the largesubunit rRNA gene (Hall et al., 2004). Primers NL1 and NL4 (Kurtzman \& Robnett, 1997) were used for amplification of the D1D2 region, following the conditions described previously (Hsiao et al., 2005). Species identification by D1-D2 sequencing was determined from the best-scoring reference sequence of the BLAST output that had an identity of $\geqslant 99 \%$ with the query sequence.

\section{RESULTS AND DISCUSSION}

\section{Amplification of the ITS regions}

The ITS regions were successfully amplified from all the dermatophytes by the fungus-specific universal primers ITS1 and ITS4. The ITS fragments of the 17 species listed in Table 1 were less than $300 \mathrm{bp}$. The length of ITS1 ranged from $169 \mathrm{bp}$ (Microsporum gallinae) to $293 \mathrm{bp}$ (Epidermophyton floccosum), while the length of ITS2 ranged from $174 \mathrm{bp}$ ( $T$. terrestre) to $243 \mathrm{bp}$ (E. floccosum) (data not shown). Among the 17 dermatophyte species, $E$. floccosum could be easily recognized since it possessed the longest ITS1 (293 bp) and ITS2 (243 bp) sequences.

\section{Barcode sequences in the ITS regions}

Multiple sequence alignment demonstrated that some dermatophyte species possessed barcode sequences (or species-specific sequences) in the ITS1 and/or ITS2 regions. For $T$. soudanense, two ITS1 genotypes were found in different strains, with one genotype having a deletion of 36 bases starting at position 122, e.g. ATCC 64654 (Fig. 1). Barcode sequences were found in Trichophyton rubrum, $T$. soudanense and $T$. violaceum in the ITS1 region at positions 167, 209 and 214 (Fig. 1). In the ITS2 region, barcode sequences also appeared in T. rubrum at positions 106 and 124 (Fig. 2). In addition, a variable number (ranging from 6 to 15) of AT repeats starting at position 164 was seen for strains of $T$. soudanense and T. violaceum (Fig. 2). In contrast, the number of AT repeats was relatively constant (six or seven) in strains of T. rubrum. These barcode sequences may be useful for differentiating species of $T$. rubrum, T. soudanense and T. violaceum when the results of conventional identification are ambiguous. Clinical isolates of the three Trichophyton species also displayed the same barcode sequences shown in Figs 1 and 2 (data not shown). Editing of the PCR product sequences to remove non-ITS sequences helps in the recognition of these barcode sequences at the indicated positions. 
Table 1. Dermatophyte strains used in this study and strains producing discrepant identification by ITS sequencing

\begin{tabular}{|c|c|c|c|}
\hline Species (teleomorph) & Reference strain ${ }^{\star}$ & Clinical isolate $\dagger$ & $\begin{array}{l}\text { No. of discrepant strains/ } \\
\text { total no. of strains }\end{array}$ \\
\hline E. floccosum & ATCC 9646, ATCC 52066 & NCKU 1862, NCKU 1973, NCKU 2827 & $0 / 5$ \\
\hline M. audouinii & $\begin{array}{l}\text { ATCC 10008, ATCC 10216, } \\
\text { ATCC } 42558\end{array}$ & $\begin{array}{l}\text { LMA 597, LMA 854, LMA 971, LMA } \\
\text { 941276, LMA 50002007, LMA 50500271, } \\
\text { LMA 50501240, LMA 50600031 }\end{array}$ & $0 / 11$ \\
\hline M. canis (Arthroderma otae) $\ddagger$ & $\begin{array}{l}\text { ATCC 10214, CBS 282.63, CBS } \\
643.74\end{array}$ & $\begin{array}{l}\text { LM 40, LMA 720, LMA 921, LMA 922, } \\
\text { LMA 94.595, LMA 94.604, LMA 5990586, } \\
\text { LMA 50000068, LMA 50000070, LMA } \\
\text { 50000071, LMA 50000091, LMA } \\
\text { 50200087, LMA 50401206, NCKU 1200, } \\
\text { NCKU 3401, NCKU 3404, NCKU } 3486\end{array}$ & $1 / 20$ \\
\hline $\begin{array}{l}\text { Microsporum cookei } \\
\text { (Arthroderma cajetanum) } \ddagger\end{array}$ & $\begin{array}{l}\text { CBS 129.67, CBS 202.66, CBS } \\
\text { 227.58, CBS 228.58; IHEM } \\
\text { 14178, IHEM } 14180\end{array}$ & LMA 94.548 & $0 / 7$ \\
\hline M. ferrugineum & $\begin{array}{l}\text { ATCC 11992, ATCC } 42560 \text {, } \\
\text { ATCC } 52060\end{array}$ & $\begin{array}{l}\text { NCKU 1582, NCKU 1627, NCKU 2513, } \\
\text { NCKU } 3385\end{array}$ & $0 / 7$ \\
\hline $\begin{array}{l}\text { M. gallinae } \\
\text { (Arthroderma grubyi) } \ddagger\end{array}$ & CBS 133.89, CBS 215.38, CBS 221.55 & & $0 / 3$ \\
\hline $\begin{array}{l}\text { M. gypseum } \\
\quad(\text { Arthroderma gypseum }) \ddagger\end{array}$ & $\begin{array}{l}\text { BCRC 30542, CBS 161.69, CBS } \\
\text { 286.63, CBS } 311.61\end{array}$ & $\begin{array}{l}\text { LMA 961, LMA 90.603, LMA 93.629, LMA } \\
\text { 94.446, LMA 91.1379, LMA 98.1320, LMA } \\
\text { 98.01190, LMA 50401101, NCKU 2001, } \\
\text { NCKU 3386 }\end{array}$ & $1 / 14$ \\
\hline $\begin{array}{l}\text { M. nanum } \\
(\text { Arthroderma obtusum }) \ddagger\end{array}$ & $\begin{array}{l}\text { CBS 321.61, CBS 569.80, CBS } \\
\text { 632.82, IHEM 19092, IHEM } 21111\end{array}$ & & $0 / 5$ \\
\hline $\begin{array}{l}\text { M. persicolor } \\
\text { (Arthroderma persicolor }) \ddagger\end{array}$ & CBS 421.74 , CBS 468.74 & $\begin{array}{l}\text { LMA 90.76, LMA 92.136, 95.974, LMA } \\
\text { 95.1741, LMA 40401293, LMA 50401174 }\end{array}$ & $0 / 8$ \\
\hline T. erinacei & IHEM 15931, IHEM 20118 & & $0 / 2$ \\
\hline $\begin{array}{l}\text { T. interdigitale } \\
\text { (Arthroderma vanbreuseghemii) } \ddagger\end{array}$ & $\begin{array}{l}\text { ATCC 200099, CBS 101.68, CBS } \\
436.73\end{array}$ & $\begin{array}{l}\text { LMA 905.92, LMA 91.309, LMA 94.677, } \\
\text { LMA 95.1682, LMA 50000604, LMA } \\
\text { 50000617, LMA 50000627, LMA } \\
\text { 50300859, LMA 50300894, LMA } \\
\text { 50401331, LMA 50401377, LMA 59800858 } \\
\text { (all from human tinea pedis, except LMA } \\
\text { 50300894, LMA 50401331 and LMA } \\
\text { 50401377 from tinea unguium) }\end{array}$ & $2 / 15$ \\
\hline T. mentagrophytes & $\begin{array}{l}\text { BCRC } \underline{32066}, \text { CBS } \underline{160.66}, \text { CBS } \\
\underline{361.62}\end{array}$ & $\begin{array}{l}\text { LMA 90.791, LMA 95.1932, LMA 50100370, } \\
\text { LMA 50400833, LMA 59801326, NCKU } \\
\text { 3361, NCKU 3389, NCKU } 3534 \text { (all from } \\
\text { human tinea corporis, except LMA } \\
50100370 \text { and LMA } 50400833 \text { from tinea } \\
\text { manuum, NCKU } 3534 \text { from tinea faciei) }\end{array}$ & $11 / 11$ \\
\hline T. rubrum & $\begin{array}{l}\text { ATCC } 28188, \text { BCRC } 32805 \text {, } \\
\text { BCRC } 32806\end{array}$ & $\begin{array}{l}\text { LMA 559, LMA 569, LMA 585, LMA 590, } \\
\text { LMA 606, LMA 610, LMA 679, LMA 685, } \\
\text { LMA 9025, LMA 90.412, LMA 96.432, } \\
\text { LMA 9.7858, LMA 95.00311; NCKU 1213, } \\
\text { NCKU 3399, NCKU } 3591\end{array}$ & $0 / 19$ \\
\hline Trichophyton schoenleinii & $\begin{array}{l}\text { ATCC 22775, ATCC 22776, CBS } \\
174.40\end{array}$ & & $0 / 3$ \\
\hline T. soudanense & $\begin{array}{l}\text { ATCC } 24583 \text {, ATCC } 52936 \text {, } \\
\text { ATCC } 64654\end{array}$ & $\begin{array}{l}\text { LMA } \underline{831}, \text { LMA } \underline{835}, \text { LMA 966, LMA } \underline{979} \text {, } \\
\text { LMA 95.32, LMA 96.248, LMA } \underline{95.1336}, \\
\text { LMA 50401328, LMA 50500572, LMA } \\
\text { 50500769, LMA } \underline{50500944, \text { LMA }} \\
\text { 50600067, LMA } 59900985\end{array}$ & $6 / 16$ \\
\hline $\begin{array}{l}\text { T. terrestre } \\
\text { (Arthroderma quadrifidum) } \ddagger\end{array}$ & $\begin{array}{l}\text { CBS 117.61, CBS 464.62, CBS } \\
465.62, \text { CBS } 567.94\end{array}$ & $\begin{array}{l}\text { LMA 92.347, LMA 93.293, LMA 7971445, } \\
\text { LMA 50200212, LMA 59901091 }\end{array}$ & $0 / 9$ \\
\hline
\end{tabular}


Table 1. cont.

\begin{tabular}{|c|c|c|c|}
\hline Species (teleomorph) & Reference strain ${ }^{\star}$ & Clinical isolate $\dagger$ & $\begin{array}{l}\text { No. of discrepant strains/ } \\
\text { total no. of strains }\end{array}$ \\
\hline T. tonsurans & ATCC 10217, ATCC 10220 & $\begin{array}{l}\text { LMA 856, LMA 857, LMA 50500106, LMA } \\
50500764, \text { LMA 50600039, NCKU 3059, } \\
\text { NCKU 3156, NCKU 3166, NCKU 3364, } \\
\text { NCKU 3383, NCKU } 3549\end{array}$ & $1 / 13$ \\
\hline T. verrucosum & $\begin{array}{l}\text { ATCC 28203, ATCC 28943, } \\
\text { ATCC } 38485 \text { IHEM 5480, } \\
\text { IHEM } 17755\end{array}$ & LMA $\underline{40204990,}$ LMA $\underline{50200673}$ & $2 / 7$ \\
\hline T. violaceum & $\begin{array}{l}\text { ATCC } 24787, \text { ATCC } 28944 \\
\text { ATCC } 62858\end{array}$ & $\begin{array}{l}\text { NCKU 3164, NCKU 3264, NCKU 3372, } \\
\text { NCKU 3395, NCKU } 3415\end{array}$ & $0 / 8$ \\
\hline Total & 62 & 126 & $24 / 188$ \\
\hline
\end{tabular}

*Strains were obtained from the following collections: ATCC, American Type Culture Collection; BCRC, Bioresources Collection and Research Center; CBS, Centraalbureau voor Schimmelcultures; IHEM, Belgian Co-ordinated Collections of Micro-organisms.

$\dagger$ Underlined strains produced discrepant results between conventional methods and ITS sequencing.

$\ddagger$ Only the teleomorph name was given on the CBS website.

The Microsporum canis complex consists of a cluster of phylogenetically closely related species (Microsporum audouinii, M. canis and Microsporum ferrugineum) (Kaszubiak et al., 2004). High sequence similarities were observed in the ITS1 (99-100\% similarities) and ITS2 regions (94-100\% similarities) among members of the complex (our unpublished data). Interestingly, barcode sequences were found in the ITS2 regions at nucleotide positions 45 to 47 (a $3 \mathrm{nt}$ deletion in M. audouinii), 52 and 170 (Fig. 3). Clinical isolates of the three Microsporum species also displayed the same barcode sequences (data not shown).
T. rubrum ATCC 28188 (DQ860747)
T. rubrum 8CRC 32806 (DQ860749)
T. soudanense ATCC 24583 (OQ8860753)
T. soudanense ATCC 64654 (DQ860755)
T. violaceum ATCC 24787 (DQ860768)
T. violaceum ATCC 28944 (DQ860769)
T. raubitschekii ATCC 42631 (EU362733)
T. gourvili CBS 170.65 (EU362731)
T. rubrum ATCC 28188 (OQ860747)
T. rubrum BCRC 32806 (DQ860749)
T. soudanense ATCC 24583 (DQ860753)
T. soudanense ATCC 64654 (DQ860755)
T. violaceum ATCC 24787 (DQ860768)
T. violaceum ATCC 28944 (DQ860769)
T. raubitschekii ATCC 42631 (EU362733)
T. gourvili CBS 170.65 (EU362731)
T. rubrum ATCC 28188 (OQ860747)
T. rubrum BCRC 32806 (DQ860749)
T. soudanense ATCC 24583 (OQ860753)
T. soudanense ATCC 64654 (DQ86075)
T. violaceum ATCC 24787 (DQ860768)
T. violaceum ATCC 28944 (DQ860769)
T. raubitschekiiATCC 42831 (EU362733)
T. gourvilii CBS 170.65 (EU362731)

Fig. 1. Partial sequence alignment and barcode sequences in the ITS1 regions in species of the $T$. rubrum complex. For $T$. soudanense, two ITS1 genotypes were found in different strains, with one genotype having a deletion of 36 bases starting at position 122. In T. rubrum, the base at position 167 was $\mathrm{A}$, while the base was $\mathrm{G}$ in $T$. soudanense and $T$. violaceum. $T$. violaceum was differentiated from $T$. rubrum and $T$. soudanense by the base $\mathrm{G}$ at position 209 ; the base was $\mathrm{A}$ in $T$. rubrum and T. soudanense. A single base deletion at position 214 was found in T. violaceum. T. raubitschekii ATCC 42631 had an identical sequence to T. rubrum. T. gourvilii var. intermedium CBS 170.65, with a deletion of 36 bases starting at position 122, had identical sequence with one genotype of $T$. soudanense. All the sequences were determined in this study and have been submitted to GenBank. The species and the corresponding GenBank accession number are indicated on the left of each sequence. Only one to two strains of each species are shown. 

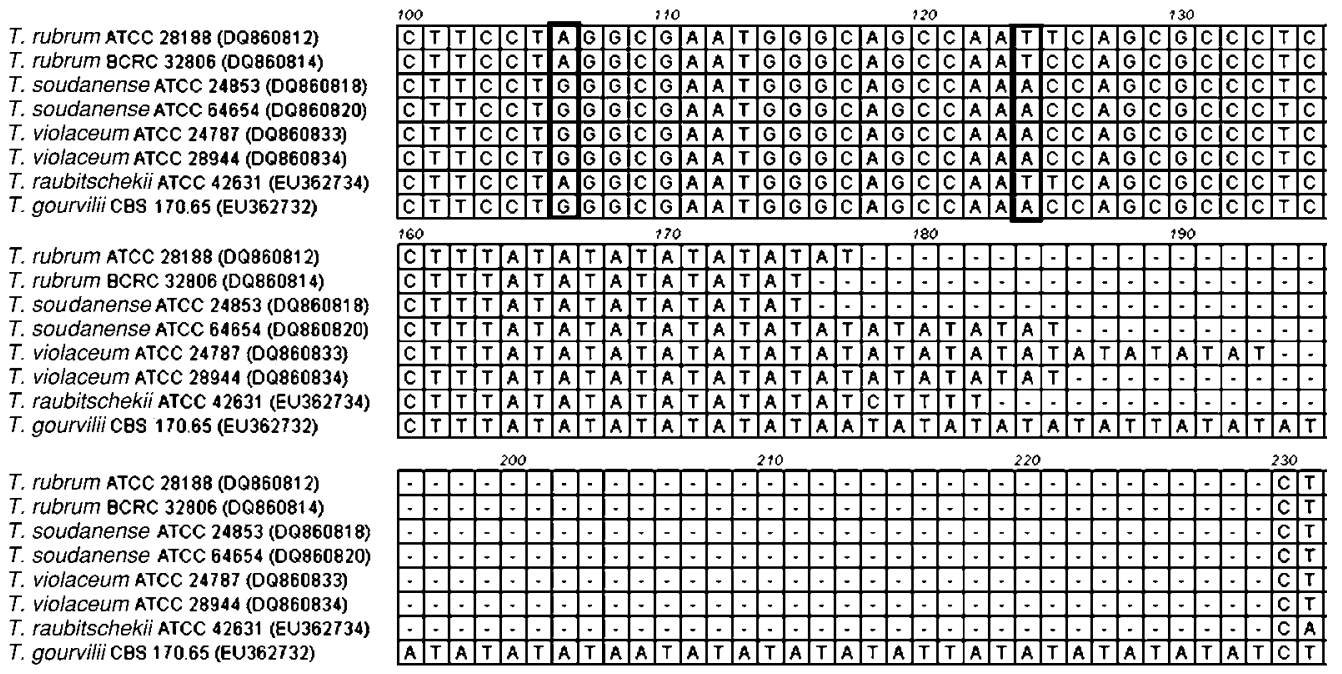

Fig. 2. Partial sequence alignment and barcode sequences in the ITS2 regions in species of the T. rubrum complex. In $T$. rubrum, the bases at positions 106 and 124 were $A$ and $T$, respectively, while they were $\mathrm{G}$ and $\mathrm{A}$, respectively, in $T$. soudanense and $T$. violaceum. T. raubitschekii ATCC 42631 had an identical sequence to T. rubrum, while $T$. gourvilii var. intermedium CBS 170.65 had an identical sequence to $T$. soudanense and $T$. violaceum, except for the number of AT repeats. The number of AT repeats at the $3^{\prime}$ end was either 6 or 7 in T. rubrum, while it ranged from 6-15 in T. soudanense and T. violaceum. T. gourvilii var. intermedium had an extraordinarily high number (31) of AT repeats. All the sequences were determined in this study and have been submitted to GenBank. The species and the corresponding GenBank accession number are indicated on the left of each sequence. Only one to two strains of each species are shown.

\section{Identification of the T. mentagrophytes complex by ITS sequencing}

The two reference strains of T. erinacei (IHEM 15931 and IHEM 20118) were correctly identified based on the constructed in-house database (Table 1). All T. interdigitale strains, except LMA 95.1682 and LMA 59800858, were correctly identified by ITS sequence analysis. T. interdigitale LMA 95.1682 was not identified, since there was no matching sequence (identity $<97 \%$ ) in the current inhouse ITS database and public databases (Table 2). At both
ITS regions, T. interdigitale LMA 59800858 (isolated from a woman with tinea pedis) displayed higher similarities with the type strain $T$. erinacei CBS 511.73 than with the neotype strain T. interdigitale BCRC 31782 (Table 2), but the strain had a similarity of $100 \%$ with the sequence of the T. interdigitale type strain BCRC $31782 \quad$ (=CBS $642.73=\mathrm{ATCC} 28146)$ at the D1-D2 region. Thus, the identity of T. interdigitale LMA 59800858 was not resolved.

Surprisingly, it was found that the three T. mentagrophytes reference strains (BCRC 32066, CBS 160.66 and CBS
M. audouinii ATCC 10008 (DQ860773) M. audouinii ATCC 10216 (DQ860774) M. canis ATCC 10214 (DQ860776)

M. canis CBS 643.74 (DQ860778) M. ferrugineum ATCC 11992 (DQ860784) M. ferrugineum ATCC 42560 (DQ880785)

M. audouinii ATCC 10008 (DQ860773) M. audouinii ATCC 10216 (DQ860774)

M. canis ATCC 10214 (DQ860776)

M. canis CBS 643.74 (DQ860778)

M. ferrugineum ATCC 11992 (DQ860784)

M. ferrugineum ATCC 42560 (DQ880785)

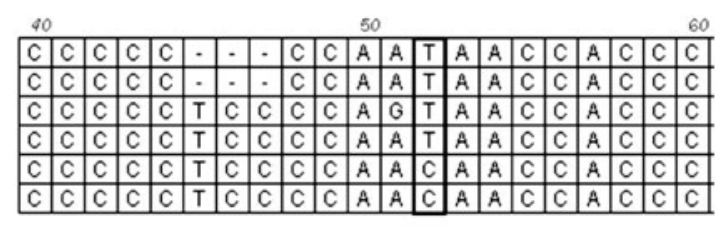

160
\begin{tabular}{|c|c|c|c|c|c|c|c|c|c|c|c|c|c|c|c|c|c|c|c|c|}
\hline G & A & C & C & G & G & C & C & G & G & T & A & G & G & C & T & G & G & C & C & T \\
\hline G & A & C & C & G & G & C & C & G & G & T & A & G & G & C & T & G & G & C & C & T \\
\hline G & A & C & C & G & G & C & C & G & G & C & A & G & G & C & T & G & G & C & C & T \\
\hline G & A & C & C & G & G & C & C & G & G & C & A & G & G & C & T & G & G & C & C & T \\
\hline G & A & C & C & G & G & C & C & G & G & C & A & G & G & C & T & G & G & C & C & T \\
\hline G & A & C & C & G & G & C & C & G & G & C & A & G & G & C & T & G & G & C & C & T \\
\hline
\end{tabular}

Fig. 3. Partial sequence alignment and barcode sequences in the ITS2 regions in species of the $M$. canis complex. In $M$. ferrugineum, the base at position 52 was $\mathrm{C}$, but it was $\mathrm{T}$ in $M$. audouinii and $M$. canis. The base at position 170 was $\mathrm{T}$ in $M$. audouinii, while it was $C$ in $M$. canis and $M$. ferrugineum. There was a 3 base deletion at positions $45-47$ in M. audouinii. All the sequences were determined in this study and have been submitted to GenBank. The species and the corresponding GenBank accession number are indicated on the left of each sequence. Only two strains of each species are shown. 
Table 2. Summary of the analysis of clinical isolates that produced discrepant results between the conventional methods and ITS sequencing

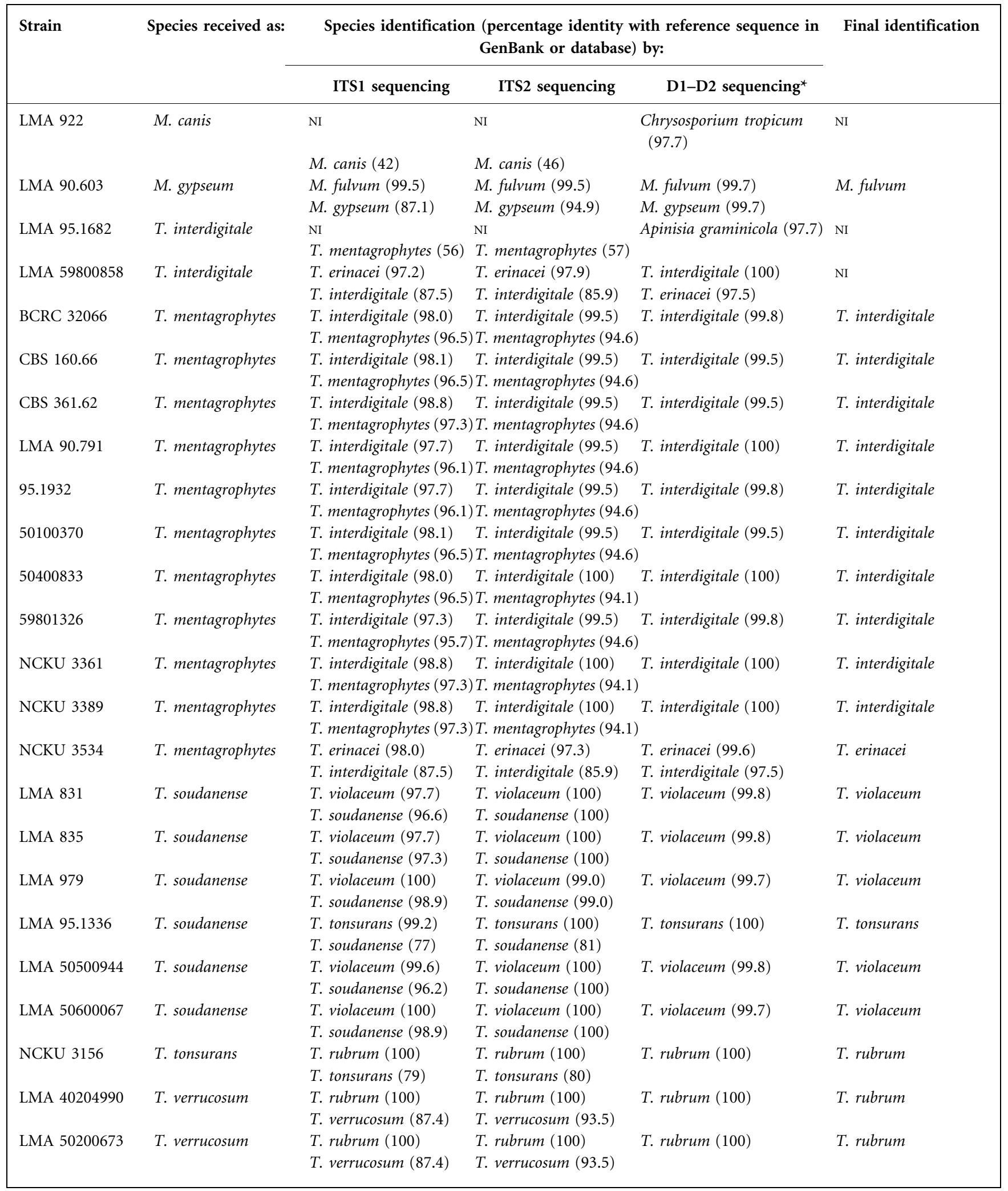

NI, Not identified

${ }^{\star}$ Results of BLAST search of GenBank. 
361.62) and all clinical isolates of the species, except the strain NCKU 3534, were identified as T. interdigitale by ITS sequence analyses. Both ITS1 and ITS2 sequences of these T. mentagrophytes strains, except NCKU 3534, had higher similarities with the type strain T. interdigitale BCRC 31782 than with the neotype strain T. mentagrophytes CBS 318.56 (Table 2). T. mentagrophytes NCKU 3534 (isolated from a woman with tinea faciei) displayed high similarities with the type strain T. erinacei CBS 511.73 at both ITS and D1D2 regions (Table 2). These results indicate that most human isolates of the $T$. mentagrophytes complex are $T$. interdigitale, with a few isolates, e.g. T. mentagrophytes NCKU 3534, being T. erinacei.

\section{Identification of the other dermatophyte species by ITS sequencing}

In addition to strains of the T. mentagrophytes complex, 11 isolates of other species produced discrepant identifications between the conventional identification methods and ITS sequencing (Table 2). M. canis LMA 922 was not identified by ITS sequence analysis, since there was no matching sequence (identity $<97 \%$ ) in the public databases. Sequencing of the D1-D2 domain also failed to identify the isolate to species level. The remaining 10 discordant clinical isolates were correctly identified to species level by ITS1 sequence analysis, as further confirmed by sequencing of the D1-D2 regions of these isolates (Table 2). Since the identity of two strains (LMA 922 and LMA 95.1682) was not resolved, they were excluded from the performance evaluation of ITS sequencing for species identification. In summary, all reference strains and clinical isolates were correctly identified by ITS1 sequencing, producing an identification rate of $100 \%(186 / 186)$. Conversely, sequence analysis of the ITS2 region revealed that five discrepant clinical isolates ( $T$. soudanense LMA 831, LMA 835, LMA 979, LMA 50500944 and LMA 50600067) had identical similarities with reference sequences of $T$. soudanense and $T$. violaceum (Table 2). This was due to the fact that $T$. soudanense and $T$. violaceum have identical ITS2 sequences, although strains of these two species may differ in the number of AT repeats at the end of the ITS2 region (Fig. 2). Thus, five clinical isolates were not identified by ITS2 sequencing, and the identification rate by sequencing of this region was $97.3 \%(181 / 186)$.

Among the clinical isolates misidentified by conventional methods, five were $T$. violaceum (misidentified as $T$. soudanense) and three were T. rubrum (misidentified as T. tonsurans or Trichophyton verrucosum) (Table 2). These results reflect that phenotypic differentiation of these Trichophyton species may be ambiguous sometimes. They suggest that the morphological features reported for $T$. soudanense, e.g. the presence of reflexive hyphae (Larone, 2002), are not an exclusive characteristic for this species. $T$. soudanense was reduced to synonymy with $T$. violaceum, based on amplified fragment length polymorphism analysis, PCR fingerprinting and the ITS sequence (Gräser $e t$ al., 2000b). T. soudanense is also recognized as a synonym of T. violaceum (De Hoog et al., 2000). But the unification of $T$. soudanense and $T$. violaceum may conceal possible evolutionary diversification, since both species have their unique geographical distributions (Larone 2002; Padhye \& Summerbell, 2005). In contrast, analysis of microsatellite DNA markers demonstrated that $T$. soudanense is somewhat closer to T. rubrum than to T. violaceum (Ohst et al., 2004). In this study, the three Trichophyton species were clearly differentiated by their barcode sequences in the ITS1 region (Fig. 1), a result that supports the idea that $T$. rubrum, $T$. soudanense and $T$. violaceum are distinct species. Very recently, Summerbell et al. (2007) reported the presence of ITS barcode sequences (single nucleotide polymorphism and repeat adenine bases) in T. tonsurans and Trichophyton equinum. They proposed that these discrete barcode sequences for each species will aid future identifications involving molecular methods.

Since Trichophyton raubitschekii and Trichophyton gourvilii are closely related to T. rubrum (Gräser et al., 2000b, 2007), the ITS regions of $T$. raubitschekii ATCC 42631 and $T$. gourvilii var. intermedium CBS 170.65 were also sequenced and aligned in this study (Fig. 1). T. raubitschekii ATCC 42631 had identical sequences to T. rubrum in both ITS regions and presented, as did T. rubrum, a small number (seven) of AT repeats at the $3^{\prime}$ end of the ITS2 region (Fig. 2). Therefore, it is most likely that $T$. raubitschekii is a variant of T. rubrum as suggested by Gräser et al. (2000b). In the ITS1 region, T. gourvilii var. intermedium CBS 170.65 had a deletion of 36 bases starting at position 122 as did one genotype of T. soudanense (Fig. 1). Analysis of the ITS2 region revealed that $T$. gourvilii var. intermedium CBS 170.65 had an identical sequence to reference sequences of $T$. soudanense and $T$. violaceum, but the strain had an extraordinary number (31) of AT repeats at the end of this region (Fig. 2). Based on these observations, it is proposed that $T$. gourvilii represents a distinct species from T. rubrum and it may not be conspecific as $T$. violaceum. T. gourvilii was considered to be a synonym of T. violaceum (Otçenásek \& Dvorák, 1975) and this was further supported by Gräser et al. (2000b).

The clinical isolate Microsporum gypseum LMA 90.603 was a misidentification of Microsporum fulvum, as revealed by its ITS1 and ITS2 sequences (Table 2). It is not easy to differentiate M. gypseum from M. fulvum on the basis of morphological criteria (De Hoog et al., 2000). To the best of our knowledge, M. fulvum is not described as a human pathogen (De Hoog et al., 2000), and the misidentification of M. fulvum as M. gypseum raises an important question about this. The isolate LMA 90.603 was recovered from a patient with an inflammatory lesion of the left thigh. So, it would be interesting to verify the morphologically based identification of M. gypseum isolates of human origin in order to determine the prevalence of $M$. fulvum in dermatophytosis.

The present method can be completed within approximately $24 \mathrm{~h}$ from isolated colonies. The results described 
herein also reveal the importance of using type (or neotype) strains as a basis for sequence comparison, especially in identifying members of the T. mentagrophytes complex (Table 2). It is to our surprise that three reference stains of T. mentagrophytes (BCRC 32066, CBS 160.66 and CBS 361.62) had higher sequence similarities with $T$. interdigitale BCRC 31782 (type strain) than with $T$. mentagrophytes CBS 318.56 (neotype strain) in both ITS and D1-D2 regions. The species status of these three reference strains should be re-evaluated.

It was noted that the ITS1 region is a better target for differentiating T. rubrum, $T$. soudanense and T. violaceum, since the latter two species had identical sequence in the ITS2 region (Fig. 2). In contrast, the ITS2 region constitutes a better target for differentiating members of the $M$. canis complex ( $M$. audouinii, $M$. canis and $M$. ferrugineum), since a few single nucleotide polymorphisms (barcode sequences) were found in the ITS2 region (Fig. 3). The reported method is straight forward, but the main issue that would detract from the application of this approach in routine clinical laboratories is the added cost. However, it is likely that many laboratories would find a use for this approach to identify a minority of atypical isolates or those leading to ambiguous results with conventional identification.

\section{ACKNOWLEDGEMENTS}

This project was supported by grants (96-2320-B-006-024-MY3 and 96-EC-17 A-10-S1-0013) from the National Science Council and Department of Economic Affairs, Taiwan, Republic of China.

\section{REFERENCES}

De Hoog, G. S., Guarro, J., Gene, J. \& Figueras, M. J. (2000). Atlas of Clinical Fungi, 2nd edn. Utrecht \& Reus: Centraalbureau voor Schimmelcultures \& University Rovirai Virgili.

El Fari, M., Tietz, H. J., Presber, W., Sterry, W. \& Gräser, Y. (1999). Development of an oligonucleotide probe specific for Trichophyton rubrum. Br J Dermatol 141, 240-245.

Gräser, Y., El Fari, M., Vilgalys, R., Kuijpers, A. F., De Hoog, G. S., Presber, W. \& Tietz, H. (1999a). Phylogeny and taxonomy of the family Arthrodermataceae (dermatophytes) using sequence analysis of the ribosomal ITS region. Med Mycol 37, 105-114.

Gräser, Y., Kuijpers, A. F., Presber, W. \& De Hoog, G. S. (1999b). Molecular taxonomy of Trichophyton mentagrophytes and T. tonsurans. Med Mycol 37, 315-330.

Gräser, Y., Kuijpers, A. F., El Fari, M., Presber, W. \& De Hoog, G. S. (2000a). Molecular and conventional taxonomy of the Microsporum canis complex. Med Mycol 38, 143-153.

Gräser, Y., Kuijpers, A. F., Presber, W. \& De Hoog, G. S. (2000b). Molecular taxonomy of the Trichophyton rubrum complex. J Clin Microbiol 38, 3329-3336.

Gräser, Y., De Hoog, S. \& Summerbell, R. C. (2006). Dermatophytes: recognizing species of clonal fungi. Med Mycol 44, 199-209.

Gräser, Y., Fröhlich, J., Presber, W. \& de Hoog, S. (2007). Microsatellite markers reveal geographic population differentiation in Trichophyton rubrum. J Med Microbiol 56, 1058-1065.
Hall, L., Wohlfiel, S. \& Roberts, G. D. (2004). Experience with the MicroSeq D2 large-subunit ribosomal DNA sequencing kit for identification of filamentous fungi encountered in the clinical laboratory. J Clin Microbiol 42, 622-626.

Hsiao, C. R., Huang, L., Bouchara, J.-P., Barton, R., Li, H. C. \& Chang, T. C. (2005). Identification of medically important molds by an oligonucleotide array. J Clin Microbiol 43, 3760-3768.

Kamiya, A., Kikuchi, A., Tomita, Y. \& Kanbe, T. (2004). PCR and PCRRFLP techniques targeting the DNA topoisomerase II gene for rapid clinical diagnosis of the etiologic agent of dermatophytosis. J Dermatol Sci 34, 35-48.

Kanbe, T., Suzuki, Y., Kamiya, A., Mochizuki, T., Fujihiro, M. \& Kikuchi, A. (2003a). PCR-based identification of common dermatophyte species using primer sets specific for the DNA topoisomerase II genes. J Dermatol Sci 32, 151-161.

Kanbe, T., Suzuki, Y., Kamiya, A., Mochizuki, T., Kawasaki, M., Fujihiro, M. \& Kikuchi, A. (2003b). Species-identification of dermatophytes Trichophyton, Microsporum and Epidermophyton by PCR and PCR-RFLP targeting of the DNA topoisomerase II genes. J Dermatol Sci 33, 41-54.

Kano, R., Okabayashi, K., Nakamura, Y., Ooka, S., Kashima, M., Mizoguchi, M., Watanabe, S. \& Hasegawa, A. (2000). Differences among chitin synthase I gene sequences in Trichophyton rubrum and T. violaceum. Med Mycol 38, 47-50.

Kaszubiak, A., Klein, S., de Hoog, G. S. \& Gräser, Y. (2004). Population structure and evolutionary origins of Microsporum canis, M. ferrugineum and M. audouinii. Infect Genet Evol 4, 179-186.

Kurtzman, C. P. \& Robnett, C. J. (1997). Identification of clinically important ascomycetous yeasts based on nucleotide divergence in the $5^{\prime}$ end of the large-subunit (26S) ribosomal DNA gene. J Clin Microbiol 35, 1216-1223.

Larone, D. H. (2002). Medically Important Fungi: a Guide to Identification, 4th edn. Washington, DC: American Society for Microbiology.

Leon-Mateos, A., Paredes-Suarez, C., Pereiro, M. \& Toribio, J. (2006). Study of the ITS region in an atypical isolate and comparison with six species of Microsporum. Mycoses 49, 452-456.

Liu, D., Pearce, L., Lilley, G., Coloe, S., Baird, R. \& Pedersen, J. (2001). A specific PCR assay for the dermatophyte fungus Microsporum canis. Med Mycol 39, 215-219.

Makimura, K., Mochizuki, T., Hasegawa, A., Uchida, K., Saito, H. \& Yamaguchi, H. (1998). Phylogenetic classification of Trichophyton mentagrophytes complex strains based on DNA sequences of nuclear ribosomal internal transcribed spacer 1 regions. J Clin Microbiol 36, 2629-2633.

Makimura, K., Tamura, Y., Mochizuki, T., Hasegawa, A., Tajiri, Y., Hanazawa, R., Uchida, K., Saito, H. \& Yamaguchi, H. (1999). Phylogenetic classification and species identification of dermatophyte strains based on DNA sequences of nuclear ribosomal internal transcribed spacer 1 regions. J Clin Microbiol 37, 920-924.

Makimura, K., Tamura, Y., Murakami, A., Kano, R., Nakamura, Y., Hasegawa, A., Uchida, K. \& Yamaguchi, H. (2001). Cluster analysis of human and animal pathogenic Microsporum species and their teleomorphic states, Arthroderma species, based on the DNA sequences of nuclear ribosomal internal transcribed spacer 1. Microbiol Immunol 45, 209-216.

Mochizuki, T., Kawasaki, M., Ishizaki, H. \& Makimura, K. (1999). Identification of several clinical isolates of dermatophytes based on the nucleotide sequence of internal transcribed spacer 1 (ITS1) in nuclear ribosomal DNA. J Dermatol 26, 276-281.

Mochizuki, T., Tanabe, H., Kawasaki, M., Ishizaki, H. \& Jackson, C. J. (2003). Rapid identification of Trichophyton tonsurans by PCR-RFLP analysis of ribosomal DNA regions. J Dermatol Sci 32, 25-32. 
Ninet, B., Isabell, J., Bontems, O., Lechenne, B., Jousson, O., Panizzon, R., Lew, D. \& Monod, M. (2003). Identification of dermatophyte species by $28 \mathrm{~S}$ ribosomal DNA sequencing with a commercial kit. J Clin Microbiol 41, 826-830.

Ohst, T., de Hoog, S., Presber, W., Stavrakieva, V. \& Gräser, Y. (2004). Origins of microsatellite diversity in the Trichophyton rubrumT. violaceum clade (dermatophytes). J Clin Microbiol 42, 4444-4448.

Otçenásek, M. \& Dvorák, J. (1975). Ecological classification of dermatophytes. Mykosen 18, 425-434.

Padhye, A. A. \& Summerbell, R. C. (2005). The dermatophytes. In Topley and Wilson's Microbiology and Microbial Infections: Medical Mycology, 10th edn, pp. 220-243. Edited by W. G. Merz \& R. J. Hay. Washington, DC: American Society for Microbiology.

Sharma, R., Rajak, R. C., Pandey, A. K. \& Gräser, Y. (2006). Internal transcribed spacer (ITS) of rDNA of appendaged and nonappendaged strains of Microsporum gypseum reveals Microsporum appendiculatum as its synonym. Antonie Van Leeuwenhoek 89, 197-202.

Summerbell, R. C., Haugland, R. A., Li, A. \& Gupta, A. K. (1999). rRNA gene internal transcribed spacer 1 and 2 sequences of asexual, anthropophilic dermatophytes related to Trichophyton rubrum. J Clin Microbiol 37, 4005-4011.

Summerbell, R. C., Moore, M. K., Starink-Willemse, M. \& Van Iperen, A. (2007). ITS barcodes for Trichophyton tonsurans and T. equinum. Med Mycol 45, 193-200.

Weitzman, I. \& Summerbell, R. C. (1995). The dermatophytes. Clin Microbiol Rev 8, 240-259.

Yoshida, E., Makimura, K., Mirhendi, H., Kaneko, T., Hiruma, M., Kasai, T., Uchida, K., Yamaguchi, H. \& Tsuboi, R. (2006). Rapid identification of Trichophyton tonsurans by specific PCR based on DNA sequences of nuclear ribosomal internal transcribed spacer (ITS) 1 region. J Dermatol Sci 42, 225-230. 